\title{
Multi-system inflammatory syndrome presenting with refractory shock in an infant, temporally associated with SARS-CoV2 infection
}

\author{
Sahana Devadas, Shruthi Ganesh*, Varun Govindarajan
}

Department of Pediatrics, Bangalore Medical College and Research Institute, Bangalore, Karnataka, India

Received: 28 April 2021

Accepted: 28 May 2021

*Correspondence:

Dr. Shruthi Ganesh,

E-mail: shruthil2g@gmail.com

Copyright: (C) the author(s), publisher and licensee Medip Academy. This is an open-access article distributed under the terms of the Creative Commons Attribution Non-Commercial License, which permits unrestricted non-commercial use, distribution, and reproduction in any medium, provided the original work is properly cited.

\begin{abstract}
Children with COVID-19 largely remain asymptomatic or mildly symptomatic with gastroenteritis or influenza like presentation. However, few of them go on to develop features of multi-system inflammatory syndrome secondary to dysregulated cytokine release, resulting even in death. We report a 45 days old infant who presented to us with fluid unresponsive shock following protracted vomiting few hours prior to arrival. Eight days prior, child was admitted in COVID Isolation centre with mild illness, after testing positive on rapid Antigen Test and discharged 3 days later. Child when brought was severely acidotic and hence electively intubated. Shock did not improve even following multiple boluses and inotropic support on mechanical ventilation. Encephalopathy, myocardial dysfunction and acute kidney injury, with elevated inflammatory markers post COVID-19 suggested multi-system inflammation syndrome in him. The infant deteriorated rapidly and succumbed even before targeted therapy could be initiated. MIS-C presenting with refractory shock is increasingly being reported in pediatric age group and these children rapidly deteriorate without early recognition and treatment. Clinicians need a heightened suspicion for cytokine storm related complications and institute early immune-modulative therapy, especially during the present COVID-19 pandemic.
\end{abstract}

Keywords: SARS CoV-2, Infantile COVID-19, PIMS-TS, Cytokine storm, Hyperinflammatory shock, Multisystem inflammatory Syndrome in children

\section{INTRODUCTION}

The novel Coronavirus, SARS CoV-2 instigated a pandemic in 2020, infecting people of all age-groups. Children account for a very small percentage of the infected population. ${ }^{1}$ They usually remain asymptomatic or may have mild flu or gastroenteritis like features, but may present with multi-system inflammatory features rarely due to a cytokine storm triggered by the virus. This aberrant and severe form of inflammation leads to an influx of pro-inflammatory mediators into the cells. ${ }^{2}$ Dysregulation of the immune response, with widespread inflammation and tissue injury, may even result in death. ${ }^{3}$ In this article, we describe the case of a one and half month-old infant with multi-system inflammatory syndrome temporally associated with SARS-CoV2 infection, resulting in the death of the infant.

\section{CASE REPORT}

We present the case of a 45 days old infant, born of $3^{0}$ consanguinities, with low grade fever eight days ago. Infant along with his parents tested positive for SARSCoV2 infection on rapid antigen testing performed on his nasopharyngeal swab. Infant was isolated at a local COVID isolation centre for 3 days, remaining only mildly symptomatic and was discharged on advice to observe strict home quarantine. On Day 9 of illness, the infant developed acute onset protracted vomiting, refusal of feeds and worsening distress. The infant was rushed to our tertiary centre for emergency management. At arrival, 
infant was lethargic, acidotic with increased work of breathing, cyanosed and severely dehydrated. Severe tachycardia with cold, clammy peripheries and delayed capillary refill time alerted us to shock. Blood gas analysis revealed a $\mathrm{pH}$ of $6.7, \mathrm{HCO}_{3}{ }^{-}$of $4 \mathrm{mEq} / \mathrm{L}$ and base excess of -35 . Infant was intubated and mechanically ventilated. Multiple fluid boluses targeting acidosis correction were given and he was initiated on inotropic support in view of fluid refractory status. Antibiotics were started suspecting septic shock, antibiotics after cultures were drawn. The infant showed no signs of clinical improvement and anuria persisted despite volume correction. Chest X-ray was normal, while screening ECHO revealed a global myocardial hypokinesia. Blood work-up revealed anemia, leukocytosis but a non-reactive CRP.

Infant's elder male sibling had succumbed 4 years ago following protracted vomiting, cause not investigated. Suspecting an acute decompensation of an Inborn error of metabolism serum ammonia (524 micromol/L) and plasma lactate $(25 \mathrm{mmoles} / \mathrm{L})$ levels were sent and found to be grossly elevated. Elevated lactate levels could be attributed to shock while the etiology for hyperammonemia in the infant remain undetermined.

Baby being post COVID status, suspecting PIMS-TS, inflammatory markers were sent and found to be grossly elevated with serum ferritin-2000 ng/dl, LDH - $1065 \mathrm{U} / \mathrm{L}$, IL-6 - $245.2 \mathrm{pg} / \mathrm{ml}$ and procalcitonin-0.17 ng/ml levels, meeting the cytokine storm post COVID-19 infection; but the delay in reports curtailed any possible therapeutic intervention and the baby succumbed within 16 hours of presentation. Blood and CSF cultures remained sterile. Repeat testing done for COVID-19 by RT-PCR following death turned out to be negetive.

\section{DISCUSSION}

SARS-CoV-2 virus causes influenza like illness, pneumonia and in severe cases acute respiratory distress syndrome in adults. Its clinical picture can be markedly different in children, most of whom are asymptomatic or have only a mild course of the disease. ${ }^{1}$ However, a novel presentation is seen in pediatric COVID-19, where the virus triggers a hyper-inflammatory state provisionally labeled pediatric inflammatory multi-system syndrome temporally associated with SARS-COV-2 (PIMS-TS). ${ }^{2}$ The varied manifestations of PIMS-TS may include toxic shock syndrome and multi-system failure or Kawasaki disease-like illness. ${ }^{3-6}$

PIMS-TS is defined as any child presenting with persistent fever, inflammation (neutrophilia, increased CRP and lymphopenia) and evidence of single or multiorgan failure with additional features which may fulfill Kawasaki disease criteria, after excluding any other microbial causes and positive or negative SARS-CoV2 PCR test. ${ }^{7}$ It occurs as a severe and delayed immune response rather than a manifestation at the time of infection with SARS-CoV-2 virus. Most children who develop PIMS remain asymptomatic or mildly symptomatic at the time of initial infection. This can be explained as priming of the immune system in predisposed children by the virus, mainly affecting the $\mathrm{T}$ cells, and later heading to widespread release of a proinflammatory cytokines causing a cytokine storm. IL-1, IL-6, TNF-alpha, IFN and other pro-inflammatory cytokines are elevated resulting in widespread tissue damage. This leads to lung injury, multi-organ failure and death. $^{8}$ Hyperammonemia may at times be the only manifestation of liver cell injury, as maybe in our case. ${ }^{9}$

Successful treatment of PIMS-TS depends on the timely identification and understanding of the mechanism of cytokine storm. IL-6 plays a major role in the development of cytokine storm. Timely initiation of corticosteroids under the cover of antibiotics with concurrent use of immunomodulators like IVIG and IL-1 and IL-6 blockade agents is the present treatment strategy of PIMS-TS with good results. ${ }^{7,10}$

\section{CONCLUSION}

PIMS-TS as a post-covid pediatric presentation is now being reported increasingly and clinicians must be aware of it, as prompt, timely identification of the features of hyper-inflammation and early initiation of treatment with corticosteroids and immunomodulators can drastically improve the outcome in these children and reduce mortality.

\section{ACKNOWLEDGEMENTS}

The authors would like to thank the patient's family for their cooperation and for consenting the publication of this manuscript.

\section{Funding: No funding sources \\ Conflict of interest: None declared \\ Ethical approval: Not required}

\section{REFERENCES}

1. Lu X, Zhang L, Du H, Zhang J, Li YY, Qu J. SARS$\mathrm{CoV}-2$ infection in children. $\mathrm{N}$ Engl $\mathrm{J}$ Med. 2020;382:1663-5.

2. Feldstein LR, Rose EB, Horwitz SM. Multisystem inflammatory syndrome in U.S. children and adolescents. N Engl J Med. 2020;383:334-46.

3. Riphagen $\mathrm{S}$, Gomez $\mathrm{X}$, Gonzalez-Martinez $\mathrm{C}$, Wilkinson N, Theocharis P. Hyperinflammatory shock in children during COVID-19 pandemic. Lancet. 2020;6736:2019-20.

4. Pouletty M, Borocco C, Ouldali N. Paediatric Multisystem inflammatory syndrome temporally associated with SARS-CoV-2 mimicking Kawasaki disease (Kawa-COVID-19): a multi-centre cohort. Ann Rheum Dis 2020;79:999-1006. 
5. Whittaker E, Bamford A, Kenny J, Kaforou M, Jones CE, Shah P. Clinical characteristics of 58 children with a pediatric inflammatory multisystem syndrome temporally associated with SARS-CoV-2. JAMA. 2020;324:259-69.

6. Cheung EW, Zachariah P, Gorelik M, Boneparth A, Kernie SG, Orange JS et al. Multisystem inflammatory syndrome related to COVID-19 in previously healthy children and adolescents in New York City. J Am Med Assoc. 2020.

7. Harwood R, Allin B, Jones CE, Whittaker E, Ramnarayan P, Ramanan A et al. A national consensus management pathway for paediatric inflammatory multisystem syndrome temporally associated with COVID-19 (PIMS-TS): results of a national Delphi process. Lancet Child Adolescent Health. 2020.

8. Ragab D, Salah Eldin H, Taeimah M, Khattar R, Salem R. The COVID-19 Cytokine Storm; What We Know So Far. Front Immunol. 2020;11:1446.
9. Honore PM, Barreto Gutierrez L, Kugener L. Liver injury without liver failure in COVID-19 patients: how to explain, in some cases, elevated ammonia without hepatic decompensation. Crit Care. 2020;24:352.

10. Balasubramanian S, Nagendran TM, Ramachandran B. Hyper-inflammatory syndrome in a child with COVID-19 treated successfully with intravenous immunoglobulin and tocilizumab. Indian Pediatr. 2020;57:681-3.

Cite this article as: Devadas S, Ganesh S, Govindarajan V. Multi-system inflammatory syndrome presenting with refractory shock in an infant, temporally associated with SARS-CoV2 infection. Int J Contemp Pediatr 2021;8:1293-5. 